\begin{tabular}{ll}
\hline \hline MINING AND METALLURGY INSTITUTE BOR & ISSN: 2334-8836 (Štampano izdanje) \\
UDK: 622 & ISSN: 2406-1395 (Online) \\
\hline \hline
\end{tabular}

UDK: $621.313(045)=111$

doi:10.5937/mmeb1804069T

Viša Tasič ${ }^{*}$ Radoš Jeremijić**, Marijana Pavlov-Kagadejev", Vladimir Despotovic ${ }^{* * *}$

\title{
GENERAL PURPOSE AC CURRENT TO DC VOLTAGE TRANSDUCER
}

\begin{abstract}
The most of previously realized and implemented Distributed Control Systems (DCS) for the electricity consumption control are based on a control at the transformer substations level (transformer output cells level). In order to make such DCS systems, applicable to a wide variety of consumers, the new components are added into the existed DCS (transducers, controllers, communication modules, etc.). In that way, the realized DCS becomes easily applicable to almost all types of electricity consumers. Also, the DCS should be low-cost, to be available to the targeted customer groups. This paper presents the characteristics of recently realized transducer (AC current to DC voltage). The application of such device in the realized DCS enables measurement the electricity consumption of almost all electrical consumers in the industrial facilities, as well as in the households.
\end{abstract}

Keywords: electricity consumption, current transducer, measurement

\section{INTRODUCTION}

The Department of Industrial Informatics in the Mining and Metallurgy Institute Bor (MMI Bor), Serbia, has a long tradition in design and application the DCS for monitoring and control the industrial processes and electricity consumption [1-5]. The electricity costs include the peak power costs at a certain time interval (e.g. 15 minutes). Such costs can be significantly reduced by switching-off or delaying to switch-on the certain electricity consumer or a group of consumers for several minutes. In this way, the electricity consumption optimization system actually limits the amount of electrical energy consumed over a designated interval of time.

Most of the previously realized systems for the electricity consumption control are based on control the transformer substations level (cells level). In order to create the DCS applicable to a wide variety electricity consumers, the new components are introduced (transducers, controllers, communication modules, etc.). The new DCS should satisfy a requirement that the measurement accuracy remains unchanged in relation to

\footnotetext{
* Mining and Metallurgy Institute Bor, Zeleni bulevar 35, 19210 Bor, Serbia,

e-mail:visa.tasic@irmbor.co.rs

** Dielectric DOO, Dr Milovanovića 15, 19210 Bor, Serbia

*** University of Belgrade, Technical Faculty in Bor, Vojske Jugoslavije 12, 19210 Bor, Serbia

***** This work is supported by a Grant from the Ministry of Education and Science of the Republic of Serbia, as a part of the Project TR-33037: "Development and Application of the Distributed System for Monitoring and Control of Electrical Energy Consumption for Large Consumers," within the framework of the Technological Development Program
} 
the previously implemented systems. In this paper, the characteristics of recently realized transducer (AC current to DC voltage) are presented. The application of such devices enables measurement the electricity consumption of almost all electrical consumers in the industrial facilities, as well as in the households.

\section{DESIGN AND APPLICATION}

The electric power and current transducers are the basic elements of every electricity consumption control DCS. The AC current to DC voltage transducer (hereinafter - transducer), presented here, can be used to measure the alternating current of electricity consumers within a band determined by the power of consumer, a frequency of 50-60 Hz. Such input signal transducer converted to the output voltage signal in the range 0-5 V DC, which is galvanically separated from the input signal. That output signal is suitable for further processing by the DCS.

The transducer is housed in a standard plastic case, with the degree of protection IP20. The unit is designed for installation on a standard DIN rail $(35 \mathrm{~mm})$ in accordance with the standard EN 60715. On the front of housing (as shown in Figure 1), there are 12 terminal clamps, arranged in two rows of 6 terminals.

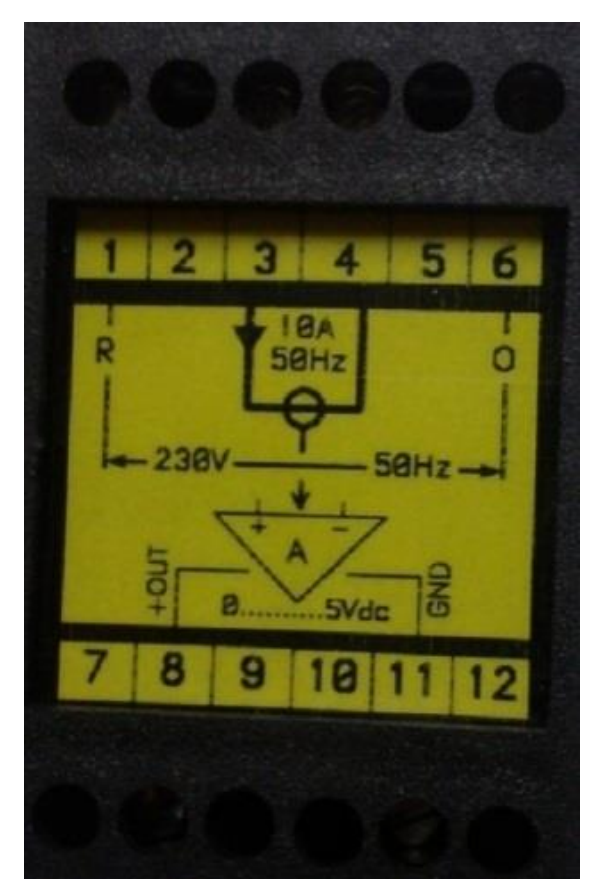

Figure 1 Front panel of the transducer

Terminals 1 and 6 are intended for the voltage supply of transducer, $230 \mathrm{~V} \mathrm{AC}$. Terminals 3 and 4 are intended for connection the main electric circuit of the electricity consumer. The wiring diagram of connecting the transducer into the electric circuit of electricity consumer is shown in Figure 2. Terminals 8 and 11 are transducer output terminals $(0-5 \mathrm{~V}$ DC, $\max 100 \mathrm{~mA}$ ). 


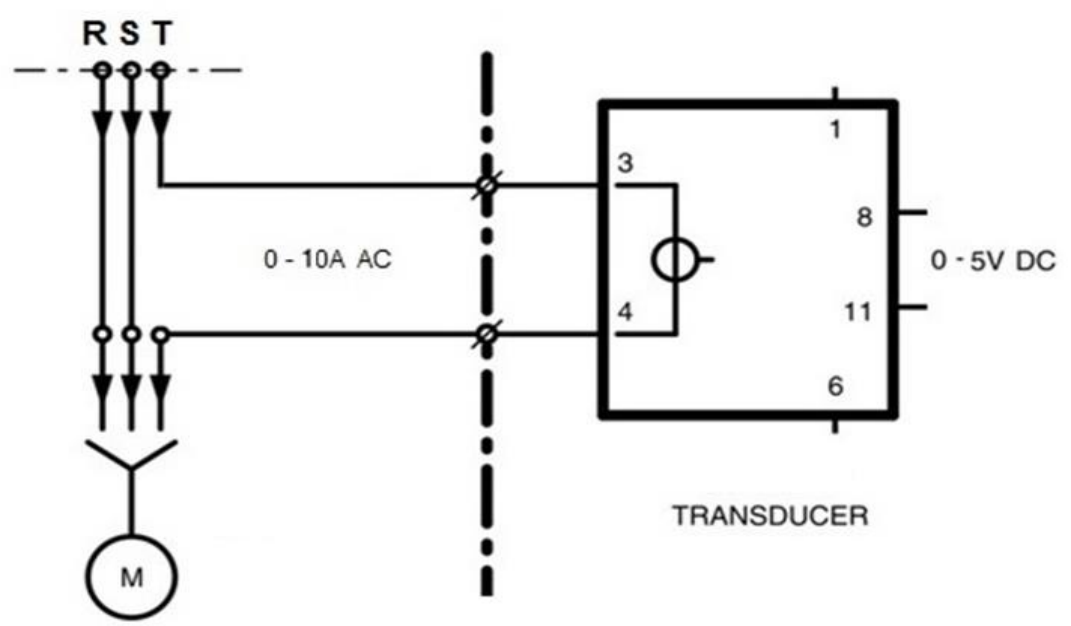

Figure 2 Wiring diagram of connecting the transducer into the electric circuit of telectricity consumer

\section{PRINCIPLE OF OPERATION}

The transducer components are located on a single-sided PCB, as shown in Figure 3. The transducer itself consists of the power supply, current transformer/ sensor, inverting amplifier, precise double-sided rectifier, and output stage. The circuit diagram of transducer is shown in Figure 4.

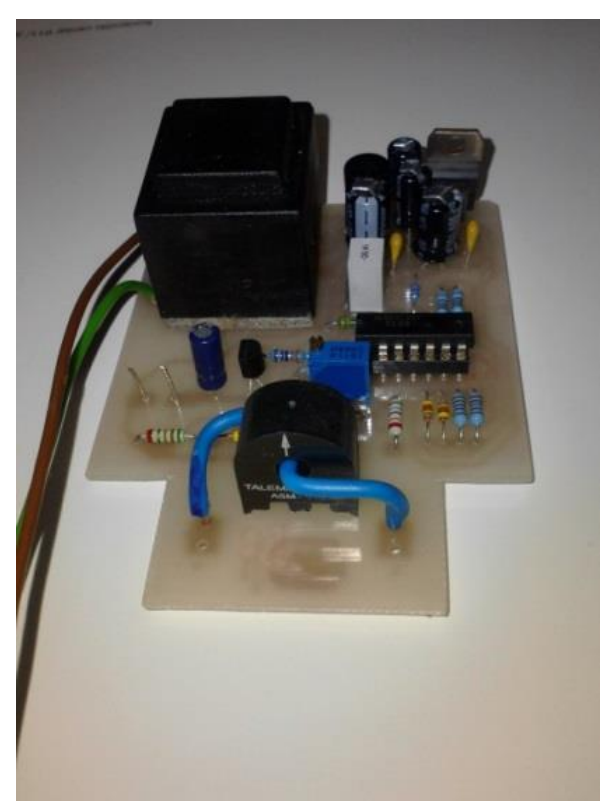

Figure 3 Single-sided transducer's PCB with the attached components 


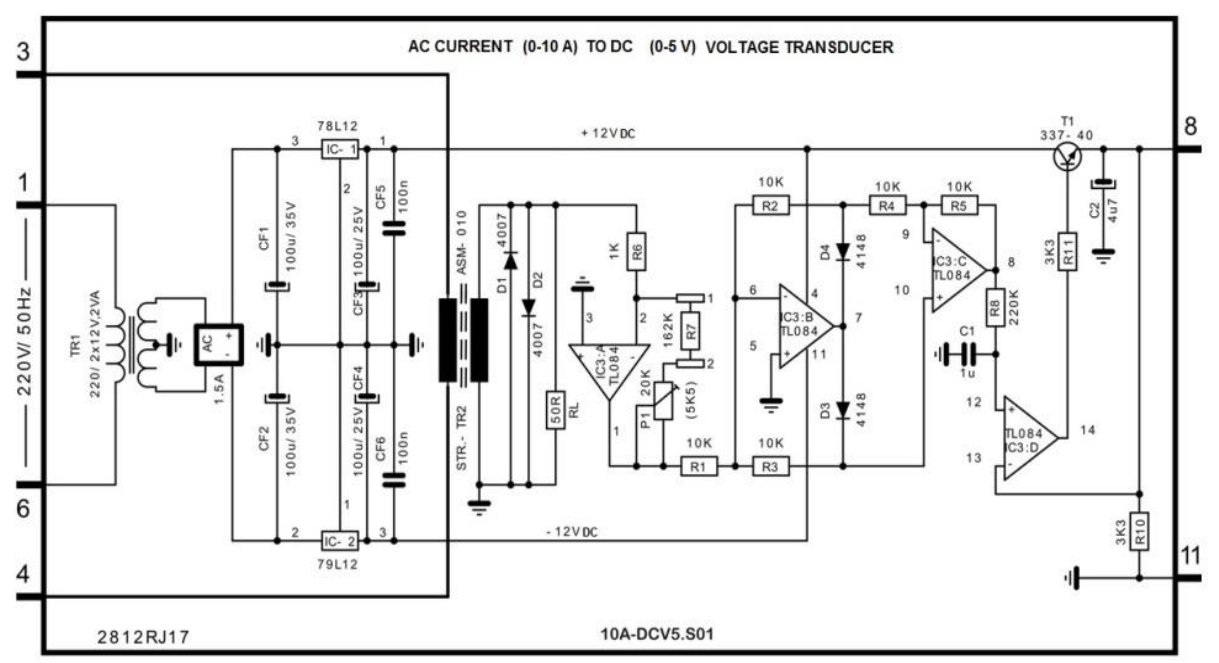

Figure 4 Circuit diagram of a transducer

\section{Power Supply}

Power supply of a transducer supplies the electronic components with $\pm 12 \mathrm{~V}$ DC. It consists of the voltage transformer TR1 (220 V AC, 2x12 V AC, 2 VA),
Graetz bridge 1.5A, voltage regulators IC1 (78L12) and IC2 (79L12), and electrolytic capacitors for filtering the supply voltage, referred as CF1-CF6 in Figure 4.

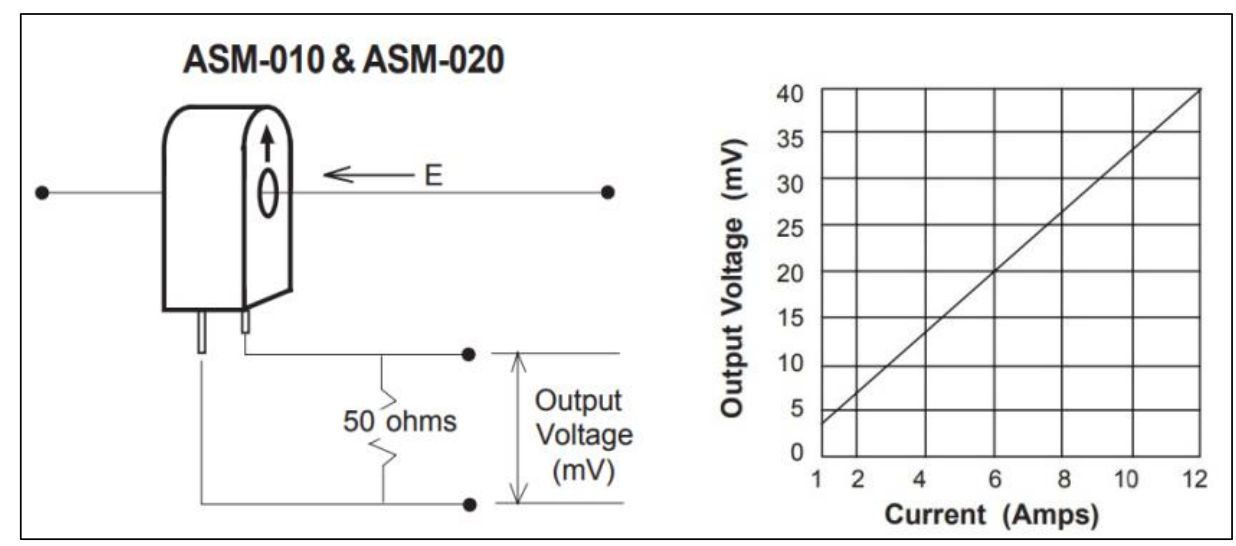

Figure 5 ASM-010 current sensor characteristics[6] 


\section{Current Transformer/Sensor}

A current transformer is an instrument transformer in which the secondary current is substantially proportional to the primary current. Current transformers are switched on the primary circuit regularly because they need to reduce the current being measured. This is the reason they practically work in a short circuit regime. The transducer, shown in Figure 3, uses a miniature current sensor type: ASM-010/TALEMA. A typical characteristic of the ASM current sensor is shown in Figure 5 [6]. The accuracy of measurement can be improved by an adequate selection the accuracy class of the current sensor and other associated electronic components.

\section{Inverting Amplifier}

An operational amplifier (OP) IC3:A with resistors R6, R7 and potentiometer P1 forming inverting amplifier arrangement is shown in Figure 4. Non-inverting input of the IC3:A is bound to ground (zero potential). Since the input voltage of an ideal OP is zero, the inverting input of the OP IC3:A is virtually on the potential of ground. Since the input current of OP is zero, all input current is closed over R7 and P1. The amplification of this amplifier is negative and equal to $-(\mathrm{R} 7+\mathrm{P} 1) / \mathrm{R} 6$. The input resistance of this amplifier is equal to the resistance of R6.

\section{Precise double-sided rectifier}

OP amplifiers IC3:B and IC3:C, diodes D3-D4 and resistors R1-R5 forming a precise double-sided rectifier are presented in Figure 4. When the input voltage is positive, the diode D4 leads and on its anode, the voltage is equal to the input one, but with the opposite polarity. In the second OP (IC3:C), this voltage is only inverted and a positive voltage with single amplification is obtained at the output of the rectifier. Both OP amplifiers work as the inverting amplifiers with unity gain. When the input voltage is negative, the feedback circuit of the first OP (IC3:B) is realized via diode D3. The input current is negative and it is divided in the ratio of 1:2, with one third going upstream, and over R2 and R4 entering the second OP, and two-thirds closing via D3. The gain is, therefore, \pm 1 depending on the polarity. The output voltage is not affected by the voltage drops on diode; hence, the circuit acts as a precision rectifier (absolute value detector). The circuit is simple because the resistors of equal resistance are used. The disadvantages of the circuit are that there are only a unit gain and small input resistance [7].

\section{Output Stage}

The OP amplifier IC3:D, transistor T1 (BC337), resistors R8, R10, R11 and capacitors $\mathrm{C} 1$ and $\mathrm{C} 2$ forming the voltage controlled current source are presented in Figure 4. The OP amplifier IC3:D acts as a voltage comparator. Non-inverting input of the OP IC3: D is connected to the output of precise double-sided rectifier through an integrator, formed by the R8 resistor and capacitor $\mathrm{C} 2$. The output stage provides a greater current availability due to the use of transistor at the output instead of using the direct output from the OP. The OP IC3:D and transistor $\mathrm{T} 1$ ensure that the voltage over resistor R10 is kept equal to that coming to the non-inverting input of the $\mathrm{OP}$ IC3:D. The voltage on the resistor R10 is proportional to the AC current at the input of the transducer. Adjustment of the transmission characteristics of the transducer is done by a potentiometer P1. 


\section{TRANSDUCER APPLICATION}

As an example of transducer application, the overload protection of the low voltage electric motor is presented (control box shown in Figure 6). Figure 7 shows a circuit diagram of the electric motor overcurrent load protection system. The protective element compares the preset maximum current load with the actual current load, measured by the transducer. When the actual current value exceeds the preset maximum, the protection system activates the sound and visual alarm. This scheme (on/off regulator) could also be applied for the electricity consumption control. If the electric motor is the electricity consumer that can be stopped for several minutes, it can be used to avoid the peak power or exceeding the allowed value for electricity consumption of the factory/facility. In such case, the additional electronics (Arduino board DCS node) has to be added into the existing overload protection system, as shown in Figure 7. Hence, the information about the actual electricity consumption of electric motor is forwarded from the Arduino board, that serves as a DCS node, via the wireless network to a DCS control level (PC workstation).

Based on the actual electricity consumption of the factory/facility, and other elements, contained in the control algorithm, the DCS decides whether to turn off the electric motor or not.

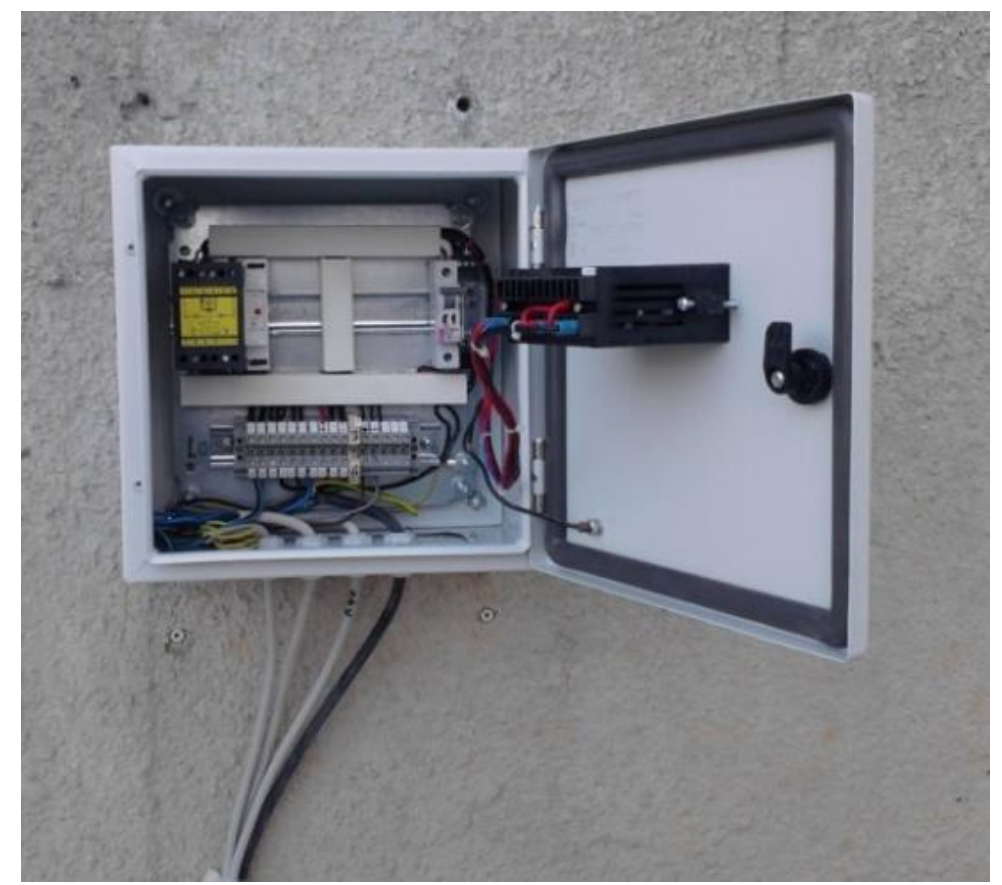

Figure 6 Transducer applied for the electric motor overload protection [8] 


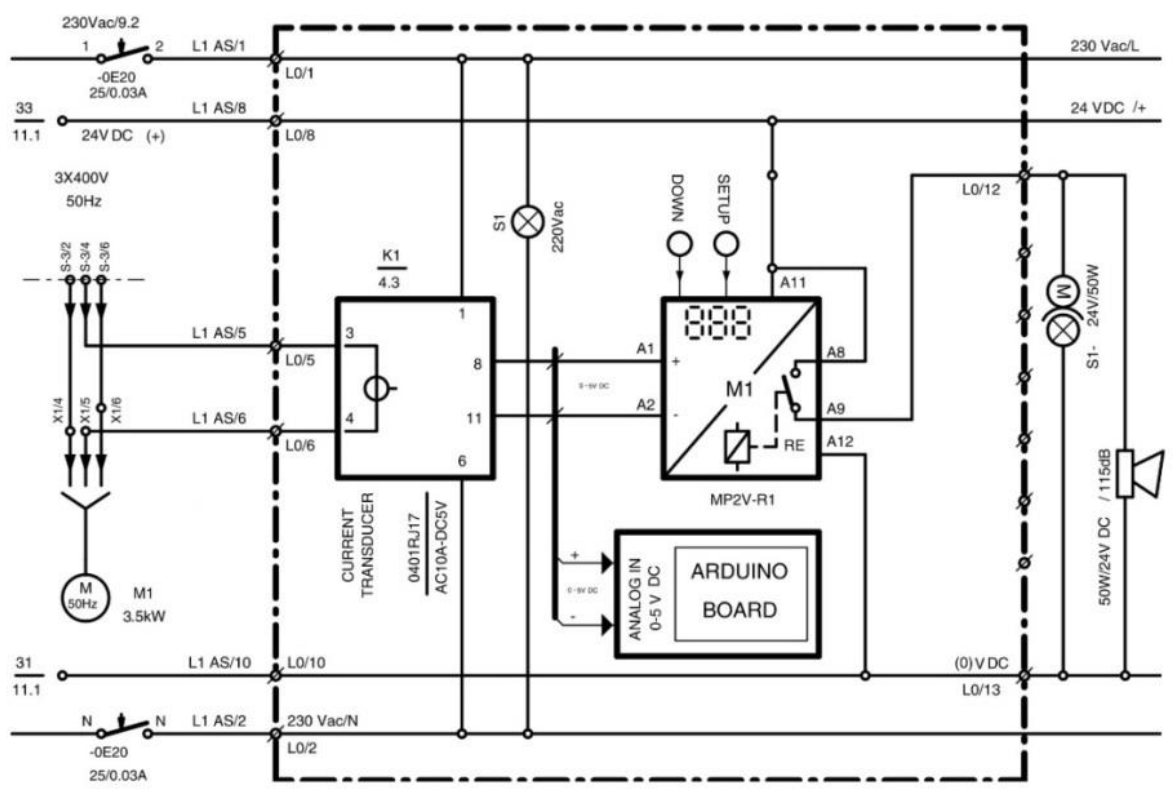

Figure 7 Circuit diagram of the electric motor overload protection system[8]

\section{CONCLUSION}

In this paper, the main characteristics of the recently realized transducer (AC current to DC voltage) are presented. The application of such devices enable measurement the electricity consumption of a wide variety of electrical consumers in the industrial facilities, as well as in the households. The device is easy to manufacture, install, calibrate and maintain. In the practical application, in the overcurrent protection systems, it has shown a good stability and reliability. It is expected that in the near future it will be extensively applied in the electricity consumption control systems.

\section{REFERENCES}

[1] Milivojević D., Tasić V., Pavlov M., Despotović V., "Synthesis of DCS in Copper Metallurgy", ICEST 2007,
Conference Proceedings, Book 2, pp. 629-631, Ohrid, FYR Macedonia, 2007.

[2] Tasić V., Milivojević D., Pavlov M., Despotović V., "Reducing the Costs of Electricity in the Copper Mining and Smelting Complex RTB Bor (Serbia) by Using of the Distributed Control System", MIPRO 2010, Conference Proceedings, pp. 664-667, Opatija, Croatia, 2010.

[3] Tasić V., Milivojević D., Pavlov M., Despotović V., Brodić D., "Microcontroller Based Systems for Peak Load Reduction, " Proceedings of 35th International Convention, MIPRO 2012, pp. 919-923, Opatija, Croatia, 21/5-25/5/2012.

[4] Tasić V., Milivojević D., Despotović V., Brodić D., Pavlov M., and 
Stojković I., "Communications in Realized Industrial networks", ICEST 2013, Conference Proceedings, pp. 619-622, Ohrid, FYR Macedonia, 2013.

[5] Tasić V., Despotović V., Brodić D., Pavlov M., Milivojević D., "Twenty Years of Monitoring and Control of Electricity Consumption in RTB Bor, Serbia", MIPRO 2013, Conference Proceedings, pp. 1134-1138, Opatija, Croatia, 2013.

[6] https://www.gotronic.fr/pj-39.pdf (accessed 18.08.2018)
[7] https://www.researchgate.net/profile/ Radojle_Radetic2/publication/3138533 83_Operacioni_pojacavaci_sa_zbirko m_sema_-_odabrana_poglavlja/links/ 58ab4422a6fdcc0e079bb850/Operacio ni-pojacavaci-sa-zbirkom-semaodabrana-poglavlja.pdf (in Serbian accessed on 18/08/2018)

[8] Tasić V., Pavlov-Kagadejev M., Jeremijić R., Despotović V., Tasić O., and Stojković I., "The Elements of Low-Cost DCS for Electricity Consumption Control," ICEST 2018, Conference Proceedings, pp. 303-307, Sozopol, Bulgaria, 2018. 